\title{
Beobachtungen des Cometen I. 1864 (entdeckt Sept. 9) auf der Leipziger Sternwarte.
}

Von dem neuesten Cometen konnten his jetzt wegen des sehr schlechten Wetters und wegen eines zwischen Leipzig und Dresden vorgenommenen telegraphischen Längenbestimmung nur die folgenden Beobachfungen gemacht werden :

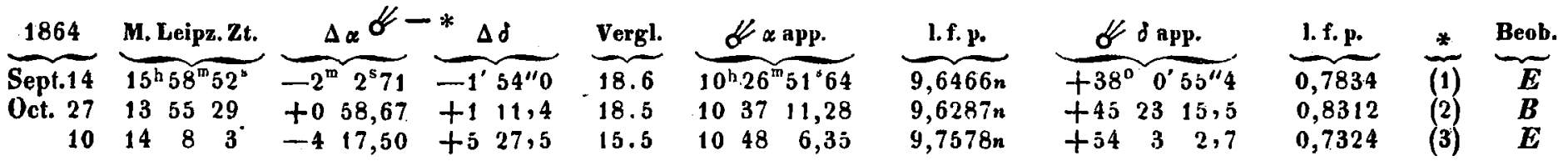

Mittlere (scheinbare) Oerter der Vergleichsterae für 1864,0, reducirt auf Wolfers.

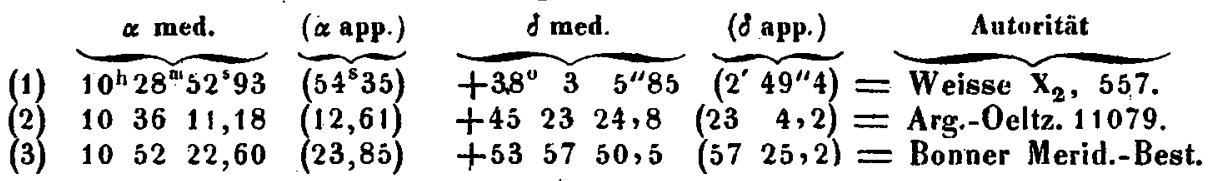

Die in Astr. Nachr. 1493 mitgetheilte Beobachtung wa' durch einen Schreibfehler von $20^{5}$ in $\Delta \alpha$ entstellt. Oct. 10 war der Comet bei allerdings nicht ganz reiner Luft äusserst schwach und schwer zu beohachten; die einzelnen Beobachtungen stimmen auch schlecht unter einander.

Bei dieser Gelegenheit berichtige ich 2 andere Fehler in den letaten Nummern der Astr. Nachr.:

A. N. 1488, p. 381 u. 382 ; Comet I. 1864 Aug. 15. Der Vergleichstern ist W. XIII, $708=$ Lal. 25438, 9, $\alpha=$

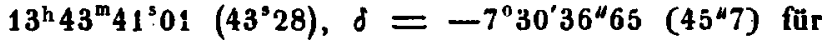
1864,0 (Aug. 15) reducirt auf Wolfers. Damit wird dann : Comet I. 1864 Aug. 15, $\alpha$ app. $=13^{\mathrm{h}} 39^{\mathrm{m}} 6^{\mathrm{s}} 03$, $\delta$ app. $=-7^{\prime} 34^{\prime} 36^{\prime \prime} 3$.

A. N. 1490 , p. 24. Bei Comet II. 1863 ist in der Columne : „Beobachter" für Oct. 3 anstatt $B$ zu lesen: „oder $E^{\prime \prime ; ~}$ die letzten Beobachtungen. seit August 16 rühren von mir her.

Sollten mir von dem letzten Cometen, dessen Bezeichnung als Comet I. 1864 wohl gerechtfertigt ist, noch Beobachtungen gelingen, so werde ich sie baldmöglichst mittheilen.

Leipzig, 1864 Oct. 15.
K. Engelmann.

Beobachtungen und Elemente der Terpsichore (81). Von Herrn Dr. Tietjen in Berlin. Von dem Planeten 81 Terpsichnre wurden hier noch folgende Beobachtungen erhalten:

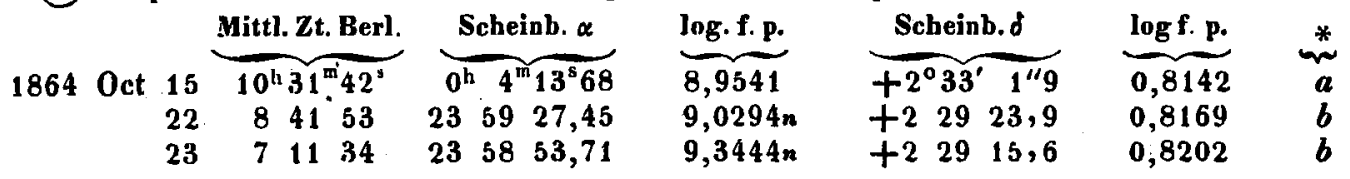

Mittlere Oerter der Vergleichsterue für 1864:

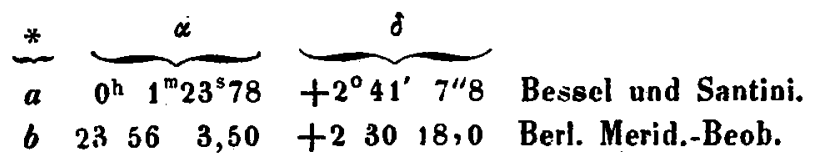

Aus den Berliner Beobachtungen von Oct. 6, 15 und 23 leitete ich nachstebende Elemente ab:

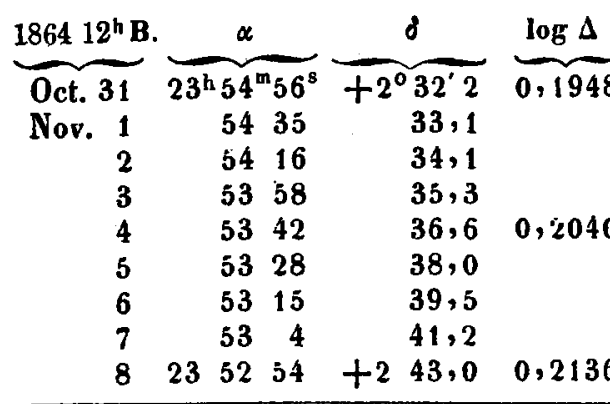

\begin{tabular}{|c|c|c|c|c|}
\hline 1864 & $\alpha$ & $\delta$ & $\log \Delta$ & 1864 \\
\hline ov. 9 & $23^{h} 52^{m} 46^{s}$ & $+2^{\circ} 44^{\prime} 9$ & & Nov. 18 \\
\hline 10 & 5240 & 47,0 & & 19 \\
\hline 11 & 5236 & 49,2 & & 20 \\
\hline 12 . & 5234 & 51,6 & 0,2237 & 21 \\
\hline 13 & 5233 & 54,1 & & 22 \\
\hline 14 & 5234 & 56,6 & & 23 \\
\hline 15 & 5236 & $+259,3$ & & 24 \\
\hline 16 & 5241 & $+32,2$ & 0,2341 & \\
\hline 17 & $\begin{array}{lll}23 & 52 & 48\end{array}$ & 5,2 & & \\
\hline
\end{tabular}

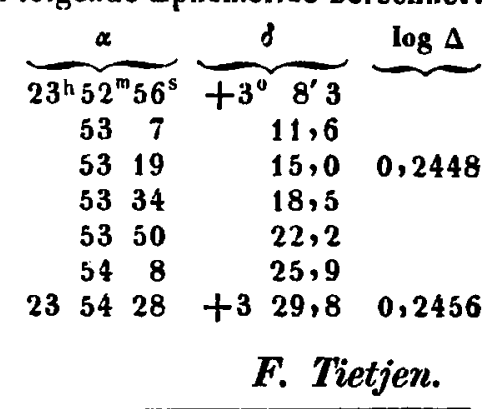

'Altona 1864. November 2.

$$
\left.\begin{array}{rl}
M & =351^{\circ} 31^{\prime} 52^{\prime \prime} 0 \\
\pi & =234012,1 \\
\Omega & =24.29,3 \\
i & =84543,0 \\
\varphi & =73235,4
\end{array}\right\} \text { mittl, Aeq. 1864,0. }
$$
Nach diesen Elementen ist folgende Ephemeride berechnet: 